\title{
INVESTIGATIONS ON THE CORROSION OF CONSTRUCTIONAL STEELS IN DIFFERENT AQUEOUS AND SIMULATED ATMOSPHERIC ENVIRONMENTS
}

\author{
Diadioly Gassama ${ }^{1,2}$, Abdou Aziz Diagne ${ }^{2,3}$, Ismaïla Yade ${ }^{2}$, Modou Fall ${ }^{2 *}$ and Sana Faty ${ }^{2}$ \\ ${ }^{1}$ UFR Sciences \& Technologies, Université de Thiès, Thiès, Senegal \\ ${ }^{2}$ Laboratory of Organic Physical Chemistry and Environmental Analyses, Department of \\ Chemistry, Faculty of Sciences and Techniques, Université Cheikh Anta Diop, Dakar, Senegal \\ ${ }^{3}$ MPCI, UFR SATIC Université Alioune Diop, Bambey, Senegal
}

(Received November 8, 2013; revised August 18, 2014)

\begin{abstract}
The corrosion behavior of three constructional steels used in Senegal, S235, S275 and S355, was studied in simulated atmospheric conditions in an exposure chamber above distilled water and above $3 \% \mathrm{NaCl}$ solution representing marine atmosphere by comparing the ratio of rusted to unrusted area. Electrochemical test methods (potentiodynamic tests and electrochemical impedance spectroscopy) were employed to study the steels fully immersed in acidic, near neutral and basic conditions in $0.5 \mathrm{M} \mathrm{HCl}, \mathrm{NaCl}$, and $\mathrm{NaOH}$ solutions, respectively. Results indicate that S355 and S235 steels have comparable corrosion resistance, which are much lower than that of S275.
\end{abstract}

KEY WORDS: Corrosion, Steel, Salt spray, Tafel polarization, Electrochemical impedance spectroscopy

\section{INTRODUCTION}

Steel is an alloy used in construction and mechanical engineering. Steels are necessary in almost all the fields that require technical application. The corrosion of a metal in aqueous environments results from the metal oxidation, but is not necessarily due to the oxygen dissolved in water [1]. The oxidation can also occur when other chemical species, especially aggressive ions are present. Corrosion is an electrochemical phenomenon and any approach to corrosion can only be led within the framework of an electrochemical representation of the processes involved [2]. Though the laws of the electrochemistry are the same for all materials, their practical behavior is nevertheless different and depends very often on their chemical composition and environment.

This work probes into the corrosion resistance of some types of constructional steels: S235, S275 and S355, supplied by "Pôle de Développement Industriel" (PDI), Dakar, Senegal. The wet (aqueous) corrosion is studied using electrochemical methods while the dry corrosion is analyzed using physical measurements made periodically on samples exposed during long periods of time [3-7]. Some works concerning the kinetic inquiry into the initial atmospheric corrosion is however available in the literature [8].

In this paper, the corrosion behavior of the steels were studied using two methods; surface analysis for simulated atmospheric tests and electrochemical tests (potentiodynamic and electrochemical impedance spectroscopy), for samples immersed in aqueous media. The selected steels are employed for construction purposes and are therefore exposed to conditions similar to the test conditions (marine and atmospheric condition near the coast).

\section{EXPERIMENTAL}

Sodium chloride, hydrochloric acid and potassium hydroxide used in this work were Merck products of analytical grade and were used without further purifications. Distilled water was used as the solvent. The electrochemical measurements were made on samples cut in a form of

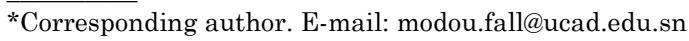


rectangular plaques by means of a universal Gruchoir pair of shears, and embedded in "Epoxy" type resins. Prior to using the plaques, a preliminary treatment was performed on their surface, which consisted of mechanically abrading with abrasive papers of variable grit size grades $(600$, 800,1000 and 1200), rinsing with distilled water and then air-drying. Atmospheric corrosion rates were evaluated on samples put in a controlled atmosphere"exposure chamber". The atmosphere in this chamber is saturated with humidity provided either by distilled water (this type of atmosphere is referred to as humid atmosphere) or by aqueous sodium chloride and hermetically closed. Samples were removed, then quickly photographed and put back in the exposure chamber at fixed regular intervals of time ( 5 days). These experiments were conducted at the ambient temperature of the laboratory. The chemical composition of test materials is provided in Table 1. The electrochemical tests were carried out in $0.5 \mathrm{M}$ aqueous solutions of $\mathrm{NaCl}, \mathrm{HCl}$ or $\mathrm{NaOH}$.

The electrochemical experiments were conducted at $25 \pm 2{ }^{\circ} \mathrm{C}$ in a classical three electrodecell, containing the working electrode, made of the specimen being studied, the counterelectrode (rolled up platinum wire) and the reference electrode $\mathrm{Ag} / \mathrm{AgCl}(+197 \mathrm{mV} / \mathrm{NHE})$. Experimentally, our measurements were made using a potentiostat - galvanostat $\mu$ Autolab type III + FRA 2 piloted by the GPES software.. The aqueous corrosion of the different steels was studied by potentiodynamic tests, with a scan rate of $0.5 \mathrm{mV} \mathrm{s}^{-1}$ and an equilibration time of 30 min. The Tafel method, a quantitative technique that allows for a fast determination of the Tafel slope constants which can provide some mechanistic insights and an estimation of corrosion rates, was employed in this work. The Tafel method consists of polarizing the electrode in the Tafel zone (we chose to work in the domain $E_{\text {corr }} \pm 250 \mathrm{mV}$ ), then in fitting the experimental values into the theoretical model of Stern-Geary [9]. Electrochemical impedance spectroscopy (EIS) measurements were made on the steel samples by applying $5 \mathrm{mV} \mathrm{AC} \mathrm{on} \mathrm{the} \mathrm{open} \mathrm{circuit}$ potential at frequencies ranging from $10 \mathrm{kHz}$ to $0.1 \mathrm{~Hz}$, with 5 points/decade. Before running any EIS measurement, the working electrode was held at its open circuit potential for an equilibrium time of $30 \mathrm{~min}$ to obtain a steady state. Both electrochemical techniques were repeated twice on each sample and the average value was reported.

Table 1. Chemical composition of test materials (wt. \%) ${ }^{*}$.

\begin{tabular}{|c|c|c|c|c|c|c|c|c|c|}
\hline Name & $\mathrm{Fe}$ & $\mathrm{C}$ & $\mathrm{Mn}$ & $\mathrm{N}$ & $\mathrm{P}$ & $\mathrm{S}$ & $\mathrm{Cu}$ & $\mathrm{Cr}$ & $\mathrm{Si}$ \\
\hline S235 steel & Bal. & 0.17 & 1.40 & 0.012 & 0.04 & 0.04 & 0.55 & - & - \\
\hline S275steel & Bal. & 0.21 & 1.50 & 0.012 & 0.04 & 0.04 & 0.55 & 0.25 & - \\
\hline S355 steel & Bal. & 0.24 & 1.60 & 0.012 & 0.04 & 0.04 & 0.55 & - & 0.55 \\
\hline
\end{tabular}

" Provided by "Pôle de Développement Industriel" (PDI), Dakar, Senegal.

\section{RESULTS AND DISCUSSIONS}

\section{Simulated atmospheric corrosion rates}

The simulated atmospheric corrosion rates are reported as a ratio (in \%) of rusted surfaces to the total surface of the samples. The surface of the samples were re-framed using the Photoshop CS5 software, while the Mesurim software was used to measure the corroded surface which is then related to the initially non corroded sample area. The exposure chamber is shown in Figure 1. As examples, presented in Figure 2-A, B and C are the photos of S235, S355 and S275 steels at $\mathrm{t}=0$, and after 30 days of exposure. The darkest zones in Figure 2-A', B' and C'correspond to the rusty parts.

When iron is exposed to the humid air in which both oxygen and water are present, the corrosion reaction occurs according to Eq. 1 [10]:

$2 \mathrm{Fe}(\mathrm{s})+\mathrm{O}_{2(\mathrm{~g})}+2 \mathrm{H}_{2} \mathrm{O} \rightarrow 2 \mathrm{Fe}^{2+}{ }_{\text {aq }}+4 \mathrm{OH}^{-}{ }_{\text {aq })} \rightarrow 2 \mathrm{Fe}(\mathrm{OH})_{2(\mathrm{~s})}$

Bull. Chem. Soc. Ethiop. 2015, 29(2) 


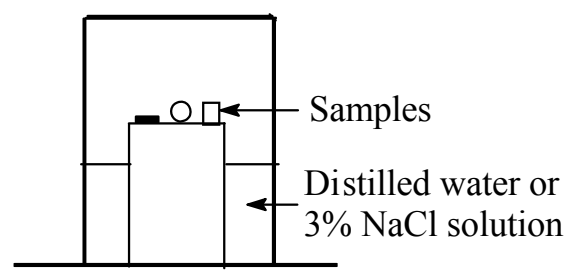

Figure 1. Dry corrosion measurement chamber.
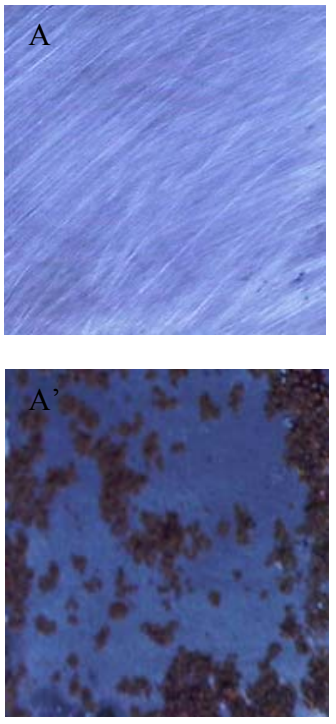
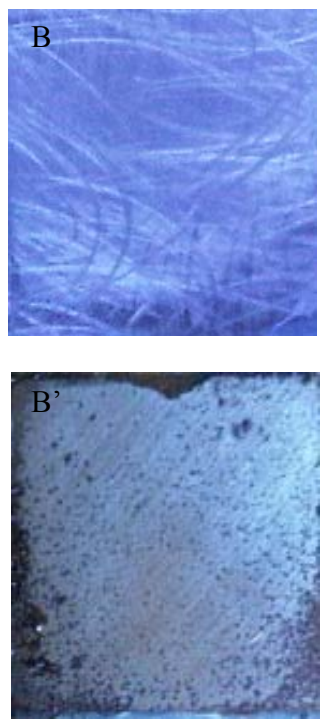
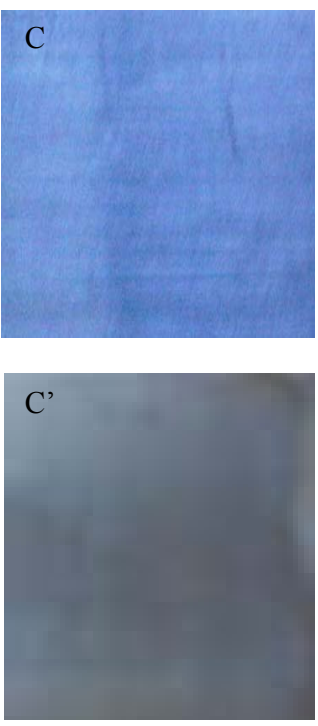

Figure 2. Photographs of S235 (A), S555 (B) and S275 (C) steels prior to introduction into the enclosure, and after 30 days of exposure to a humid atmosphere (A'), (B') and (C'). The rusty parts are dark-brown.

\section{Humid atmosphere corrosion}

After 30 days of exposition in the humid atmospheric corrosion, the different samples were rusted up to $9.1 \%$ for $\mathrm{S} 275,40.6 \%$ for $\mathrm{S} 355$ and $51.9 \%$ for S 235 . It seems that for S 355 material which is high in silicon, the abrading is not recommended because it deprives a protective constituent present on the surface. Figure 3-A represents the corrosion ratios vs. time for the different materials. After abrading of the surface, it appears that the steel corrosion ratios evolve according to the sequence: S275 < S355 < S235. This evolution can be connected with the constituents of the steels. Indeed, only S275 contains some chromium, which is added to steels to increase the resistance against oxidation [11]. The corrosion ratio seems to stabilize at approximately $8 \%$.

The surface is strongly corroded with the other steels (more than $30 \%$ after 20 days of exposure in a humidity-saturated environment). The corrosion progress is regular in S355 and S235 steels, which then undergo a more uniform corrosion $[12,13]$. Most of the passivating metals are susceptible to the localized corrosion phenomena [14]. In the case of S355, the only 
one in the study set that contains some silicon, we notice that the abrading of this metal by the abrasive paper revealed a difference of homogeneity of the surface. Silicon is used as deoxidizing (killing) agent in the melting of steel and contributes to the hardening of the ferritic phase in steels [11].

The results showed two types of corrosion: galvanic corrosion and corrosion under constraint. The metal (which has a lower redox potential than oxygen) plays the role of anode and corrodes [15]. The latter form of corrosion was observed with abraded S355 steel. The cutting of the samples by the universal Gruchoir pair of shears caused a mechanical constraint in the borders of the plaques, which entailed a fast corrosion of the borders.
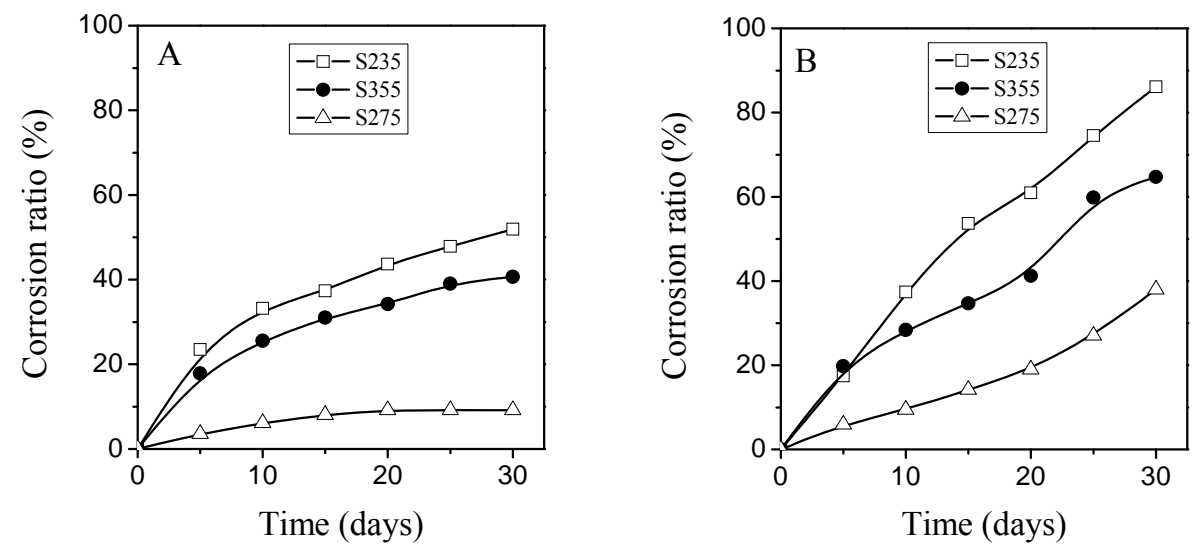

Figure 3. Corrosion ratio of the different materials as a function of time during exposure to distilled water (A) and to a $3 \%$ aqueous $\mathrm{NaCl}$ solution (B).

\section{Simulated marine atmospheric corrosion}

In order to assess the impact of salt on the atmospheric corrosion of the studied materials, plots of the corrosion ratios evolution with time (Figure 3-B), the steels being exposed above 3\% (wt) aqueous solution of $\mathrm{NaCl}$ solution and above distilled water (Figure 3-A) are presented for comparison. Figure 3-B demonstrates that, as observed during the exposure above distilled water, the corrosion ratio evolved in the order: S275 $<$ S355 $<$ S235. In addition, the corrosion ratio increased faster for all the samples exposed above $\mathrm{NaCl}$ solution compared to same exposed above distilled water. After 30 days of exposure, S235 steel had a corrosion ratio of $85 \%$, against approximately $65 \%$ for S355 material. The surface of S275 steel is mildly attacked in the atmosphere above $\mathrm{NaCl}$ solution. This metal is slightly passivated by the chromium. The corrosion occurs probably when the oxide layer is damaged locally, in certain isolated points. The speed of corrosion, after the appearance of the first rust stains, increases because of the difference of potential between the passive environment around the point, and its center increases more and more [16]. We notice a fast progress of the attack at well-localized places with S235 steel which has a good behavior towards uniform corrosion and undergoes pitting like corrosion. Under the effect of the chloride ions, the formed corrosion pits behave as cracks, the attack is deep and the pits propagate in depth with a high current density.

The external constraints have a mechanical origin from the loads applied during the division of samples into plaques by means of a universal Gruchoir pair of shears.

Kinetic study

In order to better understand the corrosion reaction kinetics, we depicted on Figure 4 the representations of the variation of the corroded surface with time. 

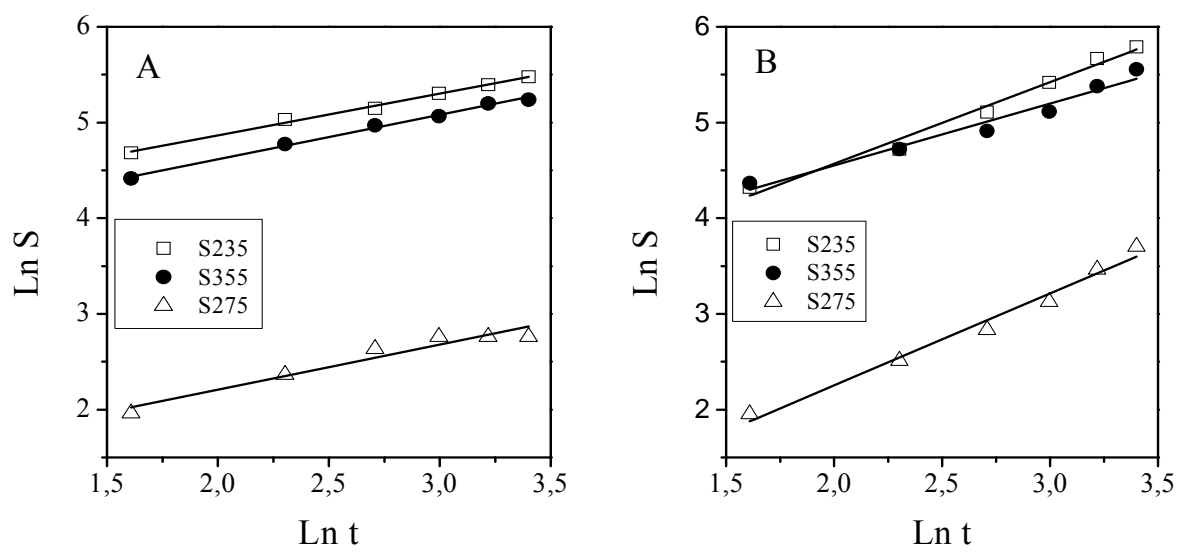

Figure 4. Evolution of the corroded surface with time in the humid atmosphere (A) and in simulated marine atmosphere (B).

The influence of the simulated marine atmosphere on different materials can be clearly observed. Whatever the corrosion type observed with the selected steels, the degradation speed is enhanced in the simulated marine atmosphere. From the literature $[17,18]$, the iron oxidation mechanism (long-term corrosion) is characterized by a linearity of the thickness of the corroded layer with $t^{n}$. The value of the exponent $n$ allows for a determining of the limiting step in the corrosion reaction mechanism. We assume that, for our case, the corroded surface varies linearly with $t^{n}$. As can be seen on Figure 4-A and 4-B, the straight lines representing Ln $S$ vs. Ln $t$ for the three steels are parallel. The humid corrosion is therefore characterized by very close slopes. The average value $(\mathrm{n} \approx 0.44)$ is compatible with a linear evolution of the corroded surface with $t^{0.5}$, indicating a corrosion kinetics controlled by the oxygen diffusion from the gaseous phase of the closed surrounding towards the interface metal $\mid$ gas.

The results obtained with the simulated marine atmosphere are less uniform. The value of the slope (0.96) indicates a clear temporal evolution of $S$ with $t$ in the case of S275. For S235 and S355 steels, we can envisage a dual control (diffusion and reaction). A reaction control is dominant for S235 (slope 0.85) while the diffusion control prevails in the case of the steel S355 (slope 0.65). This study has evidenced that the steels exposure in a simulated marine atmosphere (near the coastal zones for example) not only modifies the level of corrosion, but also the kinetics of the reaction with regard to the results obtained during an exposure in a non-salted atmosphere. The later result may be related to vapor-pressure decrease of the salt solution, compared with pure water.

\section{Tafel polarization tests}

We first studied the evolution of the open-circuit potential (OCP) of S235, S235 and S275 with time (Figure 5). The OCP decreased in the first few minutes and this may be due to the dissolution of an oxide film that was formed on the surface [19]. For S235 steel, the OCP in chloride solutions $(\mathrm{HCl}$ and $\mathrm{NaCl}$ ) increased to the more positive values in the first few minutes before stabilizing. It is clearly seen from the curves that, for the three types of steel, the OCP stabilizes after 20-25 min. The nearly constant values are reported in Table 2. We chose therefore an equilibrium time of $30 \mathrm{~min}$ for the polarization measurements.

With the Tafel polarization method, one can obtain parameters such as the corrosion current and the corrosion rate [20]. The electrochemical parameters of the steels corrosion were 
assessed in the selected acidic, neutral and basic media (Figure 6$)$. The kinetic parameters $\left(E_{\text {corr }}\right.$ and $\left.i_{\text {corr }}\right)$ are summarized in Table 2 . The variations of the corrosion current density and the corrosion potential can be used to compare the corrosion resistance of the different materials. It is noteworthy that $\mathrm{S} 275$ steel is the more corrosion resistant (lower $i_{\text {corr }}$ value) in all the tested environments (acidic, basic or neutral), whereas S235 steels have higher current densities in the considered corrosive environment.
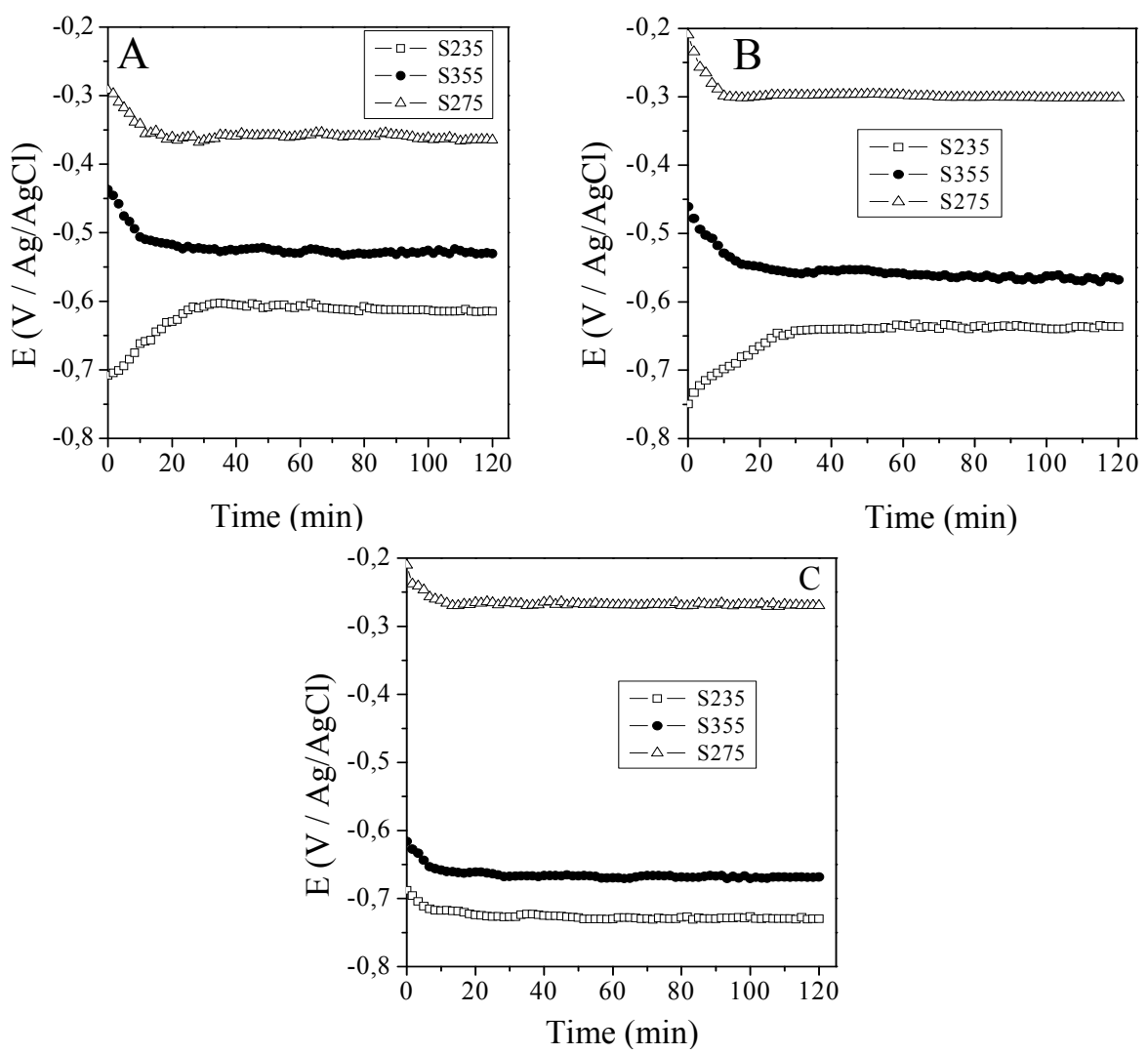

Figure 5. Variations of the open-circuit potential with time for the different steels in $0.5 \mathrm{M}$ aqueous solutions of $\mathrm{HCl}(\mathrm{A}), \mathrm{NaCl}(\mathrm{B})$ and $\mathrm{NaOH}(\mathrm{C})$.

The effect of the corrosive environment $\mathrm{pH}$ is also noticeable: the corrosion is generally more pronounced in the acid solution. We noticed a general diminution of the corrosion current density as the basicity increases. In the acidic medium, the iron corrosion resulted in the metal dissolution in the electrolytic solution, while in neutral, and especially basic solutions, the oxidation is accompanied with the formation of iron oxides and/or hydroxides including $\alpha-\mathrm{FeOOH}, \beta-\mathrm{FeOOH}, \gamma-\mathrm{FeOOH}, \mathrm{Fe}_{3} \mathrm{O}_{4}$ and large amounts of amorphous compounds $[3,21]$ which are deposited on the surface, so passivating the metal and slowing down its corrosion rate. As regards the influence of the $\mathrm{pH}$ on the potential, we note that the potential is shifted towards more cathodic values as the $\mathrm{pH}$ increases: $-722,-663$ and $-594 \mathrm{mV}$ $\mathrm{Ag} / \mathrm{AgCl}$ for $\mathrm{NaOH}, \mathrm{NaCl}$ and $\mathrm{HCl}$, respectively, in the case of $\mathrm{S} 235$ for example. The free corrosion potentials determined by Tafel polarization are in good agreement with the opencircuit potentials. 

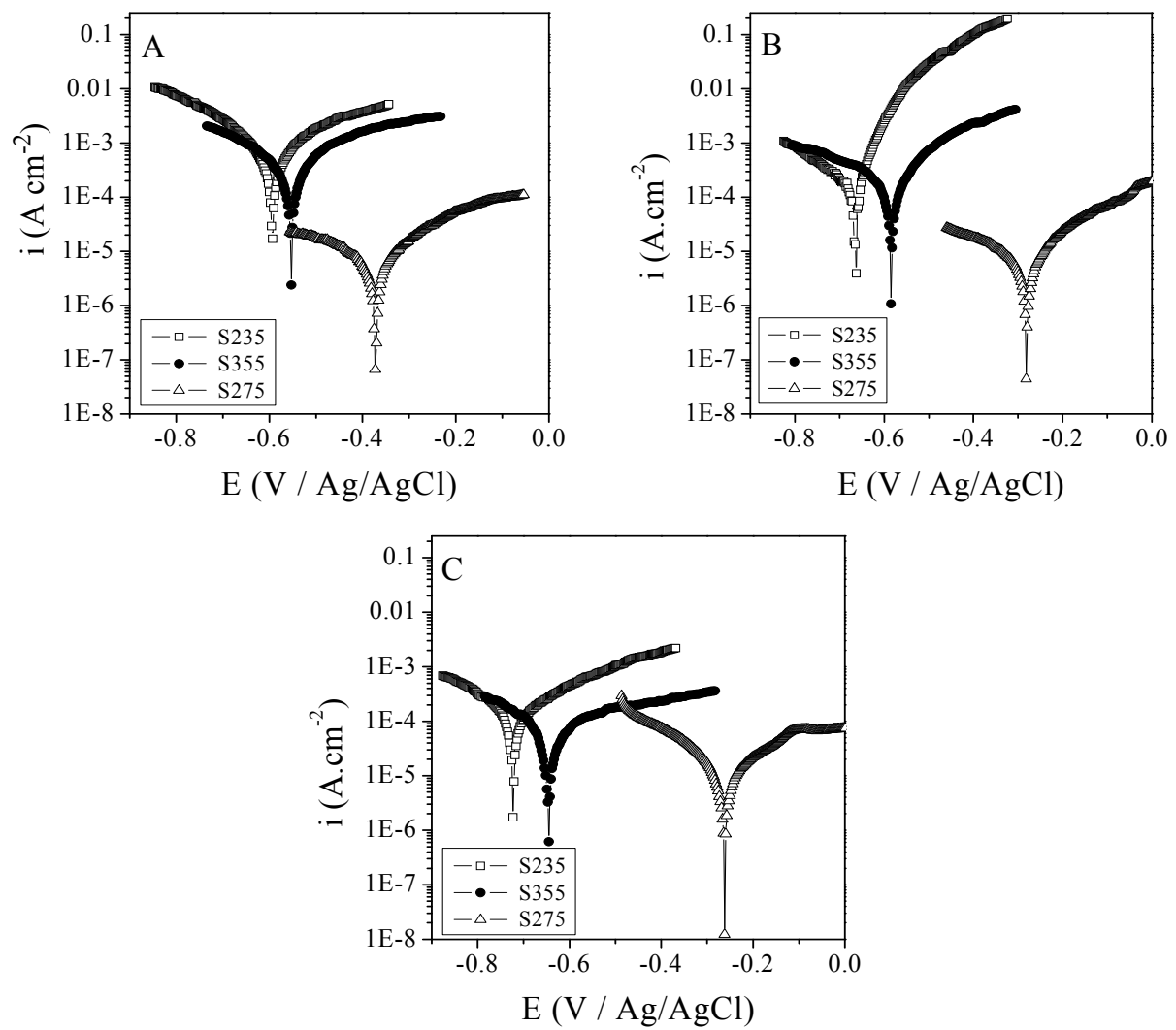

Figure 6. Polarization curves of S235, S275 and S335 in $0.5 \mathrm{M}$ aqueous solutions of $\mathrm{HCl}$ (A), $\mathrm{NaCl}(\mathrm{B})$ and $\mathrm{NaOH}(\mathrm{C})$. Scan rate: $0.5 \mathrm{mVs}^{-1}$; equilibrium time: $1800 \mathrm{~s}$.

Table 2. OCP values and Tafel polarization results of the materials in $0.5 \mathrm{M}$ aqueous solutions of $\mathrm{HCl}$, $\mathrm{NaCl}$ and $\mathrm{NaOH}$.

\begin{tabular}{|c|c|c|c|c|}
\hline & Solution test & S275 & S355 & $\mathrm{S} 235$ \\
\hline \multirow{3}{*}{$\begin{array}{c}\text { OCP } \\
(\mathrm{mV} / \mathrm{Ag} / \mathrm{AgCl})\end{array}$} & $\mathrm{HCl}$ & -362 & -530 & -612 \\
\hline & $\mathrm{NaCl}$ & -300 & -562 & -640 \\
\hline & $\mathrm{NaOH}$ & -268 & -667 & -728 \\
\hline \multirow{3}{*}{$\begin{array}{c}\mathrm{E}_{\mathrm{corr}} \\
(\mathrm{mV} / \mathrm{Ag} / \mathrm{AgCl})\end{array}$} & $\mathrm{HCl}$ & -371 & -553 & -594 \\
\hline & $\mathrm{NaCl}$ & -281 & -585 & -663 \\
\hline & $\mathrm{NaOH}$ & -262 & -644 & -722 \\
\hline \multirow{3}{*}{$\begin{array}{c}\mathrm{i}_{\text {corr }} \\
\left(\mu \mathrm{A} \mathrm{cm}^{-2}\right)\end{array}$} & $\mathrm{HCl}$ & 1.75 & 50.0 & 131 \\
\hline & $\mathrm{NaCl}$ & 0.28 & 28.0 & 35.8 \\
\hline & $\mathrm{NaOH}$ & 0.13 & 13.0 & 22.8 \\
\hline \multirow{3}{*}{$\begin{array}{c}\mathrm{R}_{\mathrm{p}} \\
\left(\Omega \mathrm{cm}^{2}\right)\end{array}$} & $\mathrm{HCl}$ & 1625 & 38 & 24 \\
\hline & $\mathrm{NaCl}$ & 1949 & 56 & 27 \\
\hline & $\mathrm{NaOH}$ & 2420 & 346 & 87 \\
\hline \multirow{3}{*}{$\begin{array}{c}\mathrm{V}_{\text {corr }} \\
(\mathrm{mm} / \text { year })\end{array}$} & $\mathrm{HCl}$ & 0.040 & 1.17 & 3.07 \\
\hline & $\mathrm{NaCl}$ & 0.007 & 0.657 & 0.840 \\
\hline & $\mathrm{NaOH}$ & 0.003 & 0.305 & 0.536 \\
\hline
\end{tabular}

Bull. Chem. Soc. Ethiop. 2015, 29(2) 
The relation of Stern-Geary [9] shows that the electrochemical corrosion rate is conversely proportional to the polarization resistance $R_{p}$ :

$i_{\text {corr }}=\frac{1}{2,303 R_{p}}\left(\frac{b_{a} b_{c}}{b_{a}+b_{c}}\right)$

According to Eq. 2, the corrosion current density increases as the polarization resistance decreases, provided that the values of $b_{\mathrm{a}}$ and $b_{\mathrm{c}}$ remain constant. The observed corrosion current density was between 0.13 and $130.5 \mu \mathrm{A} \mathrm{cm}$, and increased markedly in the following sequence: S275 < S355 < S235. Conversely, the polarization resistance was between 24 and $2420 \mathrm{k} \Omega \cdot \mathrm{cm}^{2}$, and decreased following the same sequence. S275 has the highest polarization resistance, whatever the chemical nature of the corrosive environment. Therefore, it is the metal which has the lowest corrosion current density. Nevertheless, $R_{p}$ increases with the pH. S235 steel is characterized by the lowest polarization resistance among the four samples studied in the three solutions of different acidity. Accordingly, it has the highest corrosion current density regardless the $\mathrm{pH}$ of the medium. Quite as S275, the polarization resistance increases with the $\mathrm{pH}$. With regards to the $\mathrm{S} 355$ steel, we note an opposite behaviour towards the acidity of the electrolytic solution. Finally, the $R_{p}$ value was observed to be higher in the presence of $\mathrm{NaOH}$.

The corrosion rates determined from Figure 6 are shown on Table 2. We also notice that the corrosion rate is higher in the acidic medium than in the basic environment. The minimal value is obtained in the basic solution, no matter what type of material is used. S355 and $\mathrm{S} 235$ have a relatively good behaviour in $0.5 \mathrm{M} \mathrm{NaCl}$ and $\mathrm{NaOH}$ solution as their corrosion rates were 0.305 and $0.84 \mathrm{~mm} /$ year in these media. It is enhanced in $\mathrm{HCl} 0.5 \mathrm{M}$, but did not exceed $3.07 \mathrm{~mm} /$ year. In the case of S275 steel, the measured corrosion rate was around 0.007 $\mathrm{mm} /$ year only and therefore this material has an excellent resistance against uniform corrosion. It is worthwhile to note that Danaee et al. [22] obtained recently corrosion rate values ranging from 2.55 to $2.72 \mu \mathrm{g} \mathrm{h}^{-1} \mathrm{~cm}^{-2}$ in the case of steel $4130(1 \mathrm{wt}-\% \mathrm{Cr})$ in $\mathrm{NaCl}$ and ethylene glycolwater. The results are also in agreement with those found by Ofoegbu et al. (0.002-0.709 $\mathrm{mm} /$ year) in food processing environments [23]. S275 can be considered as very corrosion resistant, even in $0.5 \mathrm{M} \mathrm{HCl}$ solution.

\section{Electrochemical impedance spectroscopy}

The corrosion behaviour of the S235 and S355 steels was investigated by EIS. The impedance spectra were recorded and displayed as Nyquist plots (Figure 7). As can be seen, the impedance diagrams show semicircles, indicating that the corrosion process is mainly charge transfer controlled [24, 25] The depressed semicircles of the Nyquist plots suggest the distribution of capacitance is due to inhomogeneous metal surface [26-30]. The shapes of the curves are quite similar and mainly consist of a large capacitive loop at higher frequencies. Similar impedance plots have been reported in the literature for the corrosion of iron [24-30].

We assumed that the systems behave like a modified Randles-circuit in which the pure capacitance is replaced by a constant-phase element (CPE) (Figure 8), which has a non-integer power dependence on the frequency [24, 31]. A CPE is often used in a model instead of a capacitor to compensate for non-homogeneity in the system [24]. Excellent fits with this model were obtained for all experimental data, the measured and simulated data matched very well. 

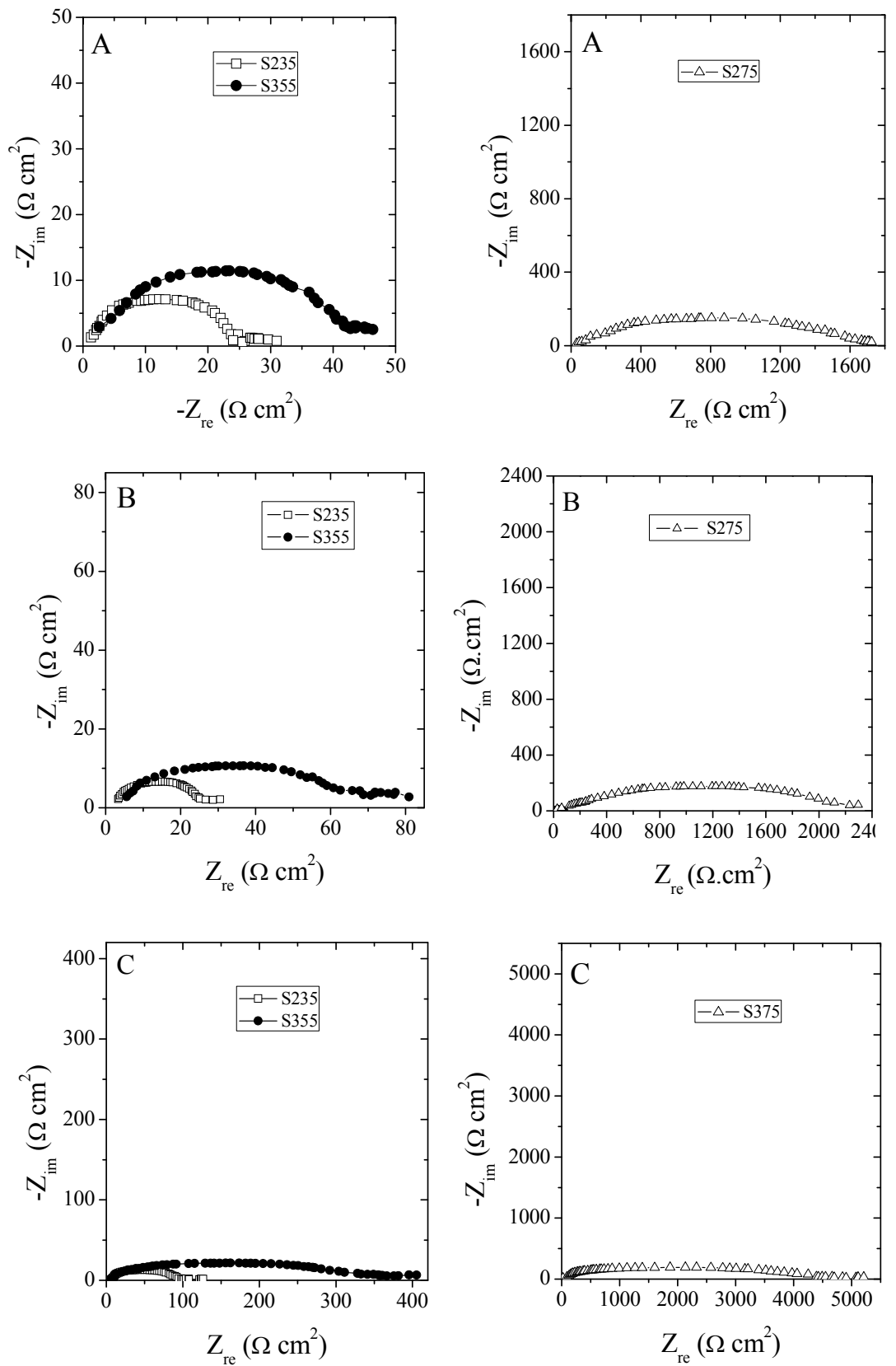

Figure 7. Impedance curves of S235, S335 and S275 in $0.5 \mathrm{M}$ aqueous solutions of $\mathrm{HCl}(\mathrm{A})$, $\mathrm{NaCl}(\mathrm{B})$ and $\mathrm{NaOH}(\mathrm{C})$. 


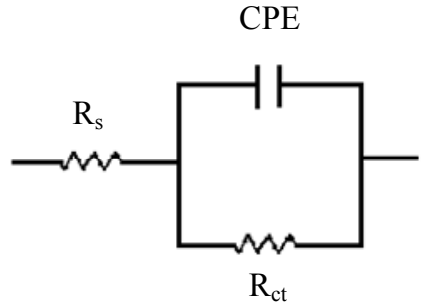

Figure 8. Electrical equivalent circuit used for modeling the interface steel/0.5 $\mathrm{M}$ aqueous solution.

The EIS fitting results are reported in Table 3. The value of the charge-transfer resistance $\left(\mathrm{R}_{\mathrm{ct}}\right)$ decreased from $\mathrm{S} 355$ to $\mathrm{S} 235$. As a large charge-transfer resistance is associated with a slower corroding system [32], these results confirm that S235 is less corrosion resistant than S355.

Table 3. Equivalent electrical circuit parameters for the corrosion process of S355 and S235 steels in the various aqueous media $(0.5 \mathrm{M})$

\begin{tabular}{|c|c|c|c|c|c|c|c|c|c|}
\hline & \multicolumn{3}{|c|}{$\mathrm{HCl}$} & \multicolumn{3}{|c|}{$\mathrm{NaCl}$} & \multicolumn{3}{|c|}{$\mathrm{NaOH}$} \\
\hline & S275 & S355 & S235 & S275 & S355 & S235 & S275 & S355 & S235 \\
\hline $\mathrm{R}_{\mathrm{s}}\left(\Omega \mathrm{cm}^{2}\right)$ & 7.7 & 4.5 & 4.1 & 8.4 & 5.6 & 5.2 & 10.4 & 7.9 & 7.7 \\
\hline $\mathrm{R}_{\mathrm{ct}}\left(\Omega \mathrm{cm}^{2}\right)$ & 1615 & 40 & 27 & 1968 & 60 & 29 & 2392 & 339 & 93 \\
\hline $\mathrm{Q}\left(\mu \mathrm{F} \mathrm{cm}^{-2}\right)$ & 4.1 & 180 & 210 & 4.3 & 156 & 179 & 4.3 & 24.9 & 79.9 \\
\hline $\mathrm{n}$ & 0.88 & 0.89 & 0.87 & 0.90 & 0.91 & 0.86 & 0.91 & 0.89 & 0.88 \\
\hline $\mathrm{C}\left(\mu \mathrm{F} \mathrm{cm}^{-2}\right)$ & 13.7 & 540 & 764 & 11.6 & 385 & 721 & 10.7 & 75.9 & 269 \\
\hline$\tau(\mathrm{s})$ & 0.022 & 0.022 & 0.021 & 0.023 & 0.023 & 0.021 & 0.026 & 0.026 & 0.025 \\
\hline
\end{tabular}

The $R_{p}$ values obtained through polarization resistance ( $\left.§ 3.2\right)$ were compared with the $R_{c t}$ obtained from electrochemical impedance spectroscopy (Figure 9) after fitting of the modified Randles-circuit. It can be observed that the resistances obtained with polarization technique are close to those obtained by EIS.

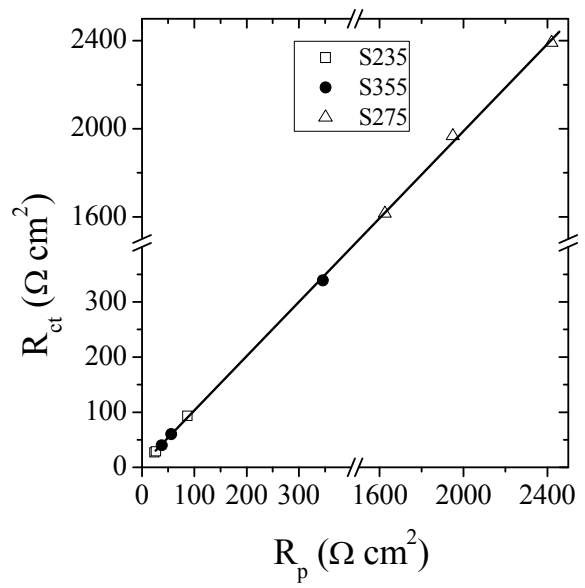

Figure 9. Comparison between $R_{p}$ (polarization resistance) and $\mathrm{R}_{\mathrm{ct}}(\mathrm{EIS})$.

Bull. Chem. Soc. Ethiop. 2015, 29(2) 
The constant phase element increased from S355 to S235, indicating enhanced faradic process for the latter steel, i.e. a higher corrosion rate. The empirical exponent $\mathrm{n}$ which should be equal to one for an ideal capacitor, measures the deviation from the ideal capacitive behavior $[30,33]$. The values of $n$ are comparable and comprised between 0.86 and 0.91 . These values close to unity indicate relatively homogenous surfaces.

In order to calculate and compare the time constants, the CPE values $(Q)$ were turned into pure capacitances $(C)$ using Eq. 3 [22, 34]:

$Q=R^{n-1} C^{n}$

A time constant $(\tau)$ was calculated using Eq. $4[22,34]$ :

$\tau=R C$

The results are given in Table 3. We obtain time constants close to 0.02 , indicating that the equivalent electrical circuits are associated with relatively rapid charge/discharge processes [22, 35]. The corrosion parameters found for $\mathrm{S} 235$ and $\mathrm{S} 355$ steels are not far from those of many steels found in the literature [36-42]. In contrast, S275 appears, in view of the experimental results, to be exceptionally corrosion resistant.

\section{CONCLUSIONS}

The exposure of three steel samples to a humidity-saturated atmosphere and a simulated marine atmosphere allowed us to study the corrosion resistance of these materials in simulated atmospheric conditions. The initial atmospheric corrosion rate evaluated by measurements of the attacked surface at different intervals of times, revealed vulnerability to corrosion depending on the elements added to iron to form these steels. While S235 undergoes a uniform corrosion, S275 steel, which contains $0.25 \%$ of chromium, is sensitive to the localized corrosion phenomena. Whatever the type of corrosion noticed for the used steels, the degradation is accelerated by the presence of the $\mathrm{Cl}^{-}$ions. The kinetic study of the reaction of initial atmospheric corrosion revealed a diffusional control, which is however slightly modified simulated marine atmosphere. The electrochemical study of the aqueous corrosion confirmed the ranking of the steels made from the atmospheric corrosion study and testified to the hydrochloric acid being the most corrosive environment for these general construction steels. Both the electrochemical methods (polarization and EIS) show that S355 and S235 steels have a comparable corrosion resistance which is much lower than for S275.

Finally, these materials are predisposed to atmospheric corrosion in coastal zones, but seem to have good resistance against aqueous corrosion. Works on the corrosion inhibition of this class of steels is going on in our laboratory.

\section{ACKNOWLEDGEMENTS}

The authors are indebted to M.M. Moustapha Sène, Boubacar Kane and Serigne Modou Touré of Pôle de Développement Industriel (PDI, Avenue Félix Eboué, BP. 63, Dakar, Senegal) for the supplying of the steel sheets and their fruitful discussions.

\section{REFERENCES}

1. Swaddle, T.W. Inorganic Chemistry: An Industrial and Environmental Perspective, Corrosion of Metals, Academic Press: San Diego; 1997; 327.

2. Krakowiak, S.; Darowicki, K.; Slepski, P. Electrochim. Acta 2005, 50, 2699.

3. Nishimura, T.; Katayama, H.; Noda, K.; Kodama, T. Corros. Sci. 2000, 42, 1611.

4. Hoerlé, S.; Mazaudier, F.; Dillmann, Ph.; Santarini, G. Corros. Sci. 2004, 46, 1431.

5. Chen, Y.Y.; Tzeng, H.J.; Wei, L.I.; Wang, L.H.; Oung, J.C.; Shih, H.C. Corros. Sci. 2005, 47, 1001. 
6. Natesan, M.; Venkatachari, G.; Palaniswamy, N. Corros. Sci. 2006, 48, 3584.

7. Burger, E.; Fénart, M.; Perrin, S. Neff, D.; Dillmann, P. Corros. Sci. 2011, 53, 2122.

8. Cai, J.-P.; Lyon, S.B. Corros. Sci. 2005, 47, 2956.

9. Stern, M.; Geary, A.L. J. Electrochem. Soc. 1957, 104, 56.

10. Atkins, P.W.; Jones, L.L. Chimie: Molécules, Matière, Métamorphoses, W.H. Freeman and Co: New York; 1998.

11. Chase Alloys Ltd, UK, Effects of alloying elements in steel; available at: http://www.chasealloys.co.uk/contact-us/index.html, accessed on 2008.

12. von Baeckmann, W.; Schwenk, W.; Prinz, W. Handbook of Cathodic Corrosion Protection: Theory and Practice of Electrochemical Protection Processes, 3rd ed., Gulf Pub. Co.: Houston; 1997.

13. Nobel Pujol - Lesueur, V. Ph.D. Thesis, University Paris 6 - Université Pierre et Marie Curie; France; 2004.

14. Refaey, S.A.M.; Taha, F.; Abd El-Malak, A.M. Appl. Surf. Sci. 2004, 21, 175.

15. Laycock, N.J.; Noh, J.S.; White, S.P.; Krouse, D.P. Corros. Sci. 2005, 47, 3140.

16. Fossati, A.; Borgioli, F.; Galvanetto, E.; Bacci, T. Corros. Sci. 2006, 48, 1513.

17. Graedel, T.E.; Frankenthal, R.P. J. Electrochem. Soc. 1990, 137, 2385.

18. Lapuerta, S. Ph.D. Thesis, University Claude Bernard - Lyon; France; 2005.

19. Sherif El-Sayed M.; Potgieter J.H.; Comins J.D.; Cornish L.; Olubambi P.A.; Machio C.N. Corros. Sci. 2009, 51, 1364.

20. Kelly, R.G.; Scully, J.R.; Shoesmith D.W.; Buchheit, R.G. Electrochemical Techniques in Corrosion Engineering, Marcel Decker Inc.: New York; 2003.

21. Zhou, Y.; Chen, J.; Xu, Y.; Liu, J. J. Mater. Sci. Technol. 2013, 29, 168.

22. Danaee, I.; Niknejad Khomami, M.; Attar, A.A. J. Mater. Sci. Technol. 2013, 29, 89.

23. Ofoegbu, S.U.; Ofoegbu, P.U.; Neife, S.I.; Okorie, B.A. J. Appl. Sci. Environ. Manage. 2011, 15, 135.

24. Morad, M.S. Corros. Sci. 2000, 42, 1307.

25. Bentiss, F.; Lebrini, M.; Vezin, H.; Chai, F.; Traisnel, M.; Lagrenée, M. Corros. Sci. 2009, 51, 2165.

26. Pajkossy, T. J. Electroanal. Chem. 1994, 364, 111.

27. Popova, A.; Raicheva, S.; Sokolova, E. Langmuir 1996, 12, 2083.

28. Morad, M.S. Mat. Chem. Phys. 1998, 60, 188.

29. Lopez, D.A.; Simison, S.N.; de Sanchez S.R. Electrochim. Acta 2003, 48, 845.

30. Garcés, P.; Saura, P.; Méndez, A.; Zornoza, E.; Andrade, C. Corros. Sci. 2008, 50, 498.

31. Macdonald, J.R. Impedance Spectroscopy-Emphasizing Solid Materials and Systems, WileyInterscience: New York; 1987.

32. Khaled, K.F. Electrochim. Acta 2003, 48, 2493.

33. Stoynov, Z.B.; Grafov, B.M.; Savova-Stoynova, B.; Elkin, V.V. Electrochemical Impedance, Nauka: Moscow; 1991.

34. Tamil Sevil, S.; Raman, V.; Rajendran, N. J. Appl. Electrochem. 2003, 33, 1175.

35. Outirite, M.; Lagrenée, M.; Lebrini, M.; Traisnel, M.; Jama, C.; Vezin, H.; Bentiss, F. Electrochim. Acta 2010, 55, 1670.

36. Ramesh Saliyan V.; Adhikari A.V. Corros. Sci. 2008, 50; 55.

37. Prabhu, R.A.; Venkatesha, T.V.; Shanbhag, A.V.; Praveen, B.M.; Kulkarni, G.M.; Kalkhambkar, R.G. Mater. Chem. Phys. 2008, 108, 283.

38. Mahdavian, M.; Attar, M.M. Corros. Sci. 2009, 51, 409.

39. Ahamad, I.; Prasad, R.; Quraishi, M.A. Corros. Sci. 2010, 52, 1472.

40. Zhang, F.; Pan, J.; Claesson, P.M. Electrochim. Acta 2011, 56, 1636.

41. Javadian, S.; Yousefi, A.; Neshati, J. Appl. Surf. Sci. 2013, 285P, 674.

42. Su, W.; Tian, Y.; Peng, S. Appl. Surf. Sci. 2014, 315, 95. 